\title{
Effects of silica-coating on surface topography and bond strength of porcelain fused to CAD/CAM pure titanium
}

\author{
Takushi FUKUYAMA, Naho HAMANO and Satoshi INO \\ Division of Minimal Intervention Prosthetic Dentistry, Department of Highly Advanced Stomatology, Kanagawa Dental University, Yokohama Clinic, \\ 3-31-6 Tsuruya-cho, Kanagawa-ku, Yokohama, Kanagawa 221-0835, Japan \\ Corresponding author, Satoshi INO; E-mail: ino@kdu.ac.jp
}

\begin{abstract}
The aim of this study was to evaluate the shear bond strength of porcelain fusing to titanium and the effects of surface treatment on surface structure of titanium. In the shear bond strength test, titanium surface treatments were: conventional, silica-coating without bonding agent, and silica-coating with bonding agent. Titanium surface treatments for analysis by the atomic force microscope (AFM) were: polishing, alumina sandblasting and silica-coating. The shear bond strength value of silica-coating with bonding agent group showed significantly higher than that of other groups. In AFM observation results, regular foamy structure which is effective for wetting was only observed in silica-coating. Therefore, this structure might indicate silicon. Silica-coating renders forms a nanoscopic regular foamy structure, involved in superhydrophilicity, to titanium surface, which is markedly different from the irregular surface generated by alumina sandblasting.
\end{abstract}

Keywords: Silica-coating, Nanostructure, Porcelain, CAD/CAM pure titanium, Shear bond strength

\section{INTRODUCTION}

Nickel chromium and gold alloys have been used for porcelain firing. However, in light of issues such as metal allergies caused by nickel-chromium alloy ${ }^{1)}$ and soaring gold prices, titanium offers advantages such as high biocompatibility, corrosion resistance and low cost. It is also applied to a metal for porcelain firing and is clinically applied ${ }^{2-10)}$. However, titanium ceramic crowns have a lower bond strength than metal ceramic crowns containing conventional nickel-chromium or gold alloy ${ }^{11-13)}$.

This is explained by the fact that titanium has powerful affinity for oxygen at high temperature and forms a thick oxide layer on a titanium surface. An oxide layer formed at less than $800^{\circ} \mathrm{C}$ is very thin and adherent; it markedly thickens at more than $900^{\circ} \mathrm{C}^{14)}$, forms a non-adherent oxide layer at $1,000^{\circ} \mathrm{C}$ and peels away from the titanium surface ${ }^{14)}$. Therefore, an oxide layer with a thick titanium surface reduces the bond strength of titanium and porcelain. In addition, since the thermal expansion coefficient of titanium is lower than that of either conventional nickel-chromium or gold alloys, porcelains applied to these metals cannot be used $^{15,16)}$. To compensate for these drawbacks, porcelains for low-temperature firing have been developed exclusively for use with titanium.

The melting points of conventional nickel-chromium and gold alloys are about $1,200^{\circ} \mathrm{C}$, whereas that of titanium is $1,668^{\circ} \mathrm{C}^{16)}$, which precludes casting ${ }^{17)}$. Furthermore, the casting surface of titanium forms an $\alpha$-case layer, which reduces the bond strength of porcelain ${ }^{18,19)}$. Therefore, titan coping fabricated by

Color figures can be viewed in the online issue, which is available at J-STAGE.

Received Sep 2, 2015: Accepted Dec 7, 2015

doi:10.4012/dmj.2015-290 JOI JST.JSTAGE/dmj/2015-290
CAD/CAM, which does not form an $\alpha$-case layer on the titanium surface, has recently been applied ${ }^{2-6)}$.

Various surface treatments of titanium have been attempted to improve bond strength, such as nitriding ${ }^{20)}$, peroxidation $^{21,22)}$ and chemical treatment ${ }^{23,24)}$. All of these include alumina sandblasting. In 1989, Guggenberger described tribochemical silica-coating (Rocatec ${ }^{\circledR}, 3 \mathrm{M}$ ESPE, Seefeld, Germany) by sandblasting with silica-coated alumina powder to form a silicate layer on an adherent surface ${ }^{25}$. Kern et al. found that tribochemical silica-coating of a titanium surface improves adhesion ${ }^{26,27)}$. However, they did not reveal the nanostructure of the treated surface, or the bond strength and mechanisms of action of CAD/CAM pure titanium and porcelain.

The present study examines the effects of tribochemical silica-coating on the surface of $\mathrm{CAD} / \mathrm{CAM}$ pure titanium and the bond strength of porcelain.

\section{MATERIALS AND METHODS}

Table 1 shows the materials used in this study.

This study consists of two kinds of analyses, which are the bond strength test and the analysis of surface topography. The bond strength test was evaluated using shear bond strength measurement and analysis of fracture surface. The analysis of surface topography was examined by contact angle measurement and observation of treated surface.

\section{Titanium specimen preparation}

Thirty-seven test specimen $(15 \times 9 \times 2 \mathrm{~mm})$ were cut from a CAD/CAM pure titanium block (GN-1 TITANIUM BLOCK, GC, Tokyo, Japan) using a low-speed precision cutting machine (ISOMET ${ }^{\circledR}$, Buehler, Chicago, IL, 
Table 1 Materials used in this study

\begin{tabular}{lccc}
\hline \multicolumn{1}{c}{ Brand name } & Composition & Production no. & Manufacturer \\
\hline GN-1 Titanium Block & Pure titanium & 1111181 & GC, Tokyo, Japan \\
Initial Ti Powder Opaque & Feldspathic porcelain & 1110071 & GC \\
Initial Ti Dentin & Feldspathic porcelain & 812041 & GC \\
Initial Ti Bonder, Bonder Liquid & $\mathrm{B}_{2} \mathrm{O}_{3}, \mathrm{La}_{2} \mathrm{O}_{3}$ & 904301 & GC \\
Rocatec $^{\circledR}$ Pre & $110 \mu \mathrm{m} \mathrm{Al2O3}$ & 572619 & 3M ESPE, Seefeld, Germany \\
Rocatec $^{\circledR}$ Plus & Silica cont. $110 \mu \mathrm{m} \mathrm{Al2O3}$ & 572618 & 3M ESPE \\
\hline
\end{tabular}

Table 2 Firing Schedules of bonding agent and porcelain

\begin{tabular}{lcccc}
\hline & Start temperature $\left({ }^{\circ} \mathrm{C}\right)$ & Rate of temperature rise $\left({ }^{\circ} \mathrm{C} / \mathrm{min}\right)$ & End temperature $\left({ }^{\circ} \mathrm{C}\right)$ & Vaccum \\
\hline Bonding agent & 450 & 55 & $810+$ \\
Opaque porcelain & 450 & 55 & 810 & + \\
Dentin porcelain & 400 & 55 & $780 \quad+$ \\
\hline
\end{tabular}

USA). The surfaces of the titanium test specimen were polished under running water using \#600 waterproof abrasive papers (Sankyo Rikagaku, Saitama, Japan), then ultrasonically cleaned in ethanol for $15 \mathrm{~min}$.

1. The bond strength test

1) Shear bond strength measurement

(1) Surface treatment

The surfaces of titanium test specimen were prepared as follows. Eight specimens were assigned for each group.

(1) Conventional group: After a bonding agent was mixed with a bonder liquid, a very thin bonding agent was applied to the titanium surface and fired according to manufacturer's recommendation ${ }^{28)}$.

(2) Silica-coating without bonding agent group: Silica-coating was conducted with $110-\mu \mathrm{m}$ silicacontaining alumina powder $\left(\right.$ Rocatec $^{\circledR}$ Plus, 3M ESPE).

(3) Silica-coating with bonding agent group: Following the treatment (2), treatment (1) was conducted.

Since sandblasting with alumina reduces the bond strengths of titanium and porcelain ${ }^{29,30)}$, alumina sandblasting before the application of a bonding agent was omitted in the conventional group. The bonding agent was fired using a firing furnace (Programat P100, Evoclar Vivadent, Tokyo, Japan) according to manufacturer's recommendation ${ }^{28)}$ (Table 2). Silicacoating was conducted using a sandblaster (Rocatec $^{\circledR}$ delta, 3M ESPE) for $15 \mathrm{~s}$ at a distance of $10 \mathrm{~mm}$ from the specimen at a pressure of $0.6 \mathrm{MPa}$.

(2) Porcelain application (Fig. 1)

Porcelain was applied to the titanium surface after preparation as described above and fired according to manufacturer's recommendation ${ }^{28)}$ (Table 2). Dentine porcelain was applied using a circular polyoxymethylene mold (diameter, $4.6 \mathrm{~mm}$; height, $2.0 \mathrm{~mm}$ ) and fired to prepare a porcelain specimen (Fig. 1-a).

The bonding area was formed as a circle with a diameter of $4.6 \mathrm{~mm}$ using a masking tape. After the application of opaque porcelain (Fig. 1-b), the porcelain specimens were mounted on it (Fig. 1-c). An excess part of the opaque porcelain was removed, followed by firing using a firing furnace (Fig. 1-d) according to manufacturer's recommendation. (Table 2). Subsequently, a specimen was fixed in an autopolymerizing resin (Fig. 1-e) (Ostron II, GC).

(3) Shear bond strength measurement

A shear bond strength test was conducted using a universal testing machine (Autograph AGS 1000B, Shimadzu, Kyoto, Japan) at a crosshead speed of 1.0 $\mathrm{mm} / \mathrm{min}$. The results were subjected to one-way analysis of variance, followed by a Fisher's least significant difference (LSD) test $(p<0.01)$ (Fig. 1-f). The number of specimens was prepared by reference to standard ISO10477 $7^{31)}$.

\section{2) Analysis of fracture surface}

After the shear bond strength test, five specimens each were randomly selected from the conventional and silica-coating with bonding agent groups. The La and Si mapping and Back Scattered Composition image (BSE image) of the fracture surface were observed with an electron probe microanalyzer (EPMA; EPMA8705, Shimadzu). Measurement parameters were set as follows: accelerating voltage, $20 \mathrm{kV}$; beam current, $2 \mathrm{nA}$; and measurement time, $0.01 \mathrm{~s}$.

As a result of EPMA analysis, cohesive failure ratios 
(a) Porcelain specimens

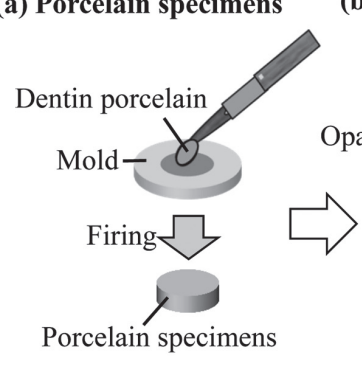

(d) Firing

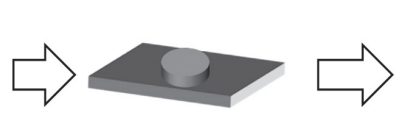

(e) Fixed

Opaque Porcelain application
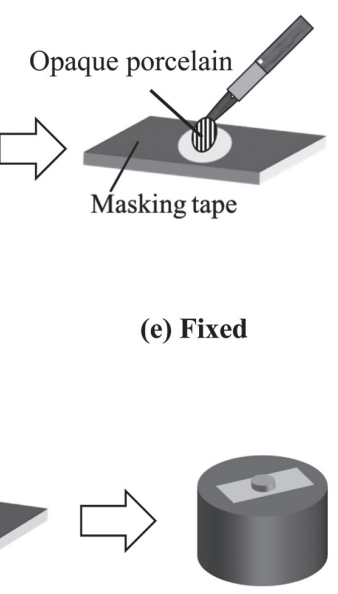

(c) Porcelain specimens were mounted

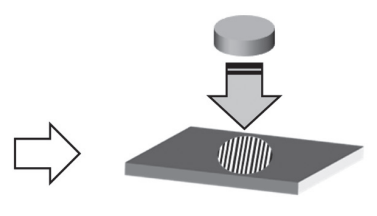

(f) Share bond strength test

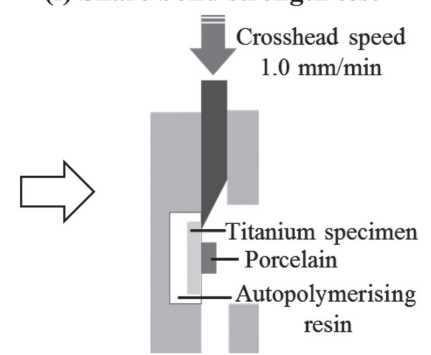

Fig. 1 Schema of porcelain application and shear-bond strength test.

and Si and La element-undetected areas in the bonding areas of each group were determined using NIH Image J software $^{32)}$. The results were analyzed using a Student's $t$-test $(p<0.01)$.

2. The analysis of surface topography

1) Contact angle measurement

Five titanium test preparations each were sandblasted with alumina (1) or coated with $\mathrm{Si}(2)$ as follows.

(1) Alumina sandblasting group: Alumina powder $\left(110 \mu \mathrm{m}\right.$, Rocatec ${ }^{\circledR}$ Pre, 3M ESPE) was injected using a sandblaster (Rocatec ${ }^{\circledR}$ delta, 3M ESPE) for $15 \mathrm{~s}$ at a distance of $10 \mathrm{~mm}$ from the specimen with a pressure of $0.6 \mathrm{MPa}$.

(2) Silica-coating group: Silica-coating was conducted in the same manner as the titanium surface treatment in the shear bond strength test.

Contact angles were measured with distilled water using an automatic dynamic contact analyzer (DCA-VZ, Kyowa Interface Science, Saitama, Japan). Each specimen was measured three times at room temperature. The contact angles were calculated using software (FAMAS, Kyowa Interface Science). The results were analyzed using a Student's $t$-test $(p<0.01)$.

2) Observation of treated surface

Each titanium test specimen was subjected to surface treatment as described below, and the titanium surfaces were observed using an Atomic Force Microscope (AFM; SPI3800n, Seiko Instruments, Chiba, Japan).

(1) Polishing: The titanium surfaces were polished under running water using \#600 waterproof abrasive papers.

(2) Alumina sandblasting: Alumina sandblasting was conducted in the same manner as the

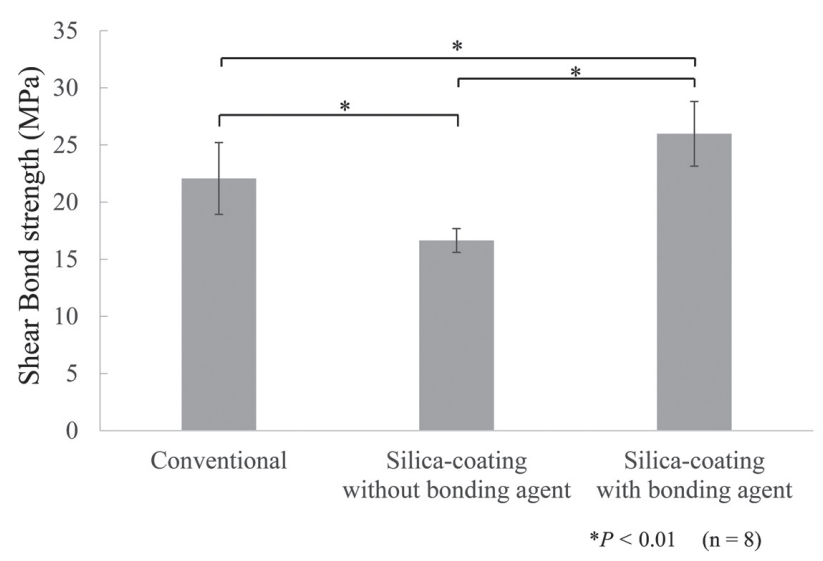

Fig. 2 Shear bond strength of each preparation. ${ }^{*} p<0.01$, statistically significant differences within groups.

treatment for titanium surface roughness.

(3) Silica-coating: Silica-coating was conducted in the same manner as the titanium surface treatment in the shear bond strength test.

\section{RESULTS}

The results of shear bond strength measurement showed significantly higher bond strengths in the conventional $(22.1 \pm 3.1 \mathrm{MPa})$ and silica-coating with bonding agent $(26.0 \pm 2.8 \mathrm{MPa})$ groups than in the silica-coating without bonding agent group (16.6 $\pm 1.0 \mathrm{MPa})$ (Fig. 2). Bond strength was significantly higher for the silica-coating with bonding agent group than for the conventional 
(a)

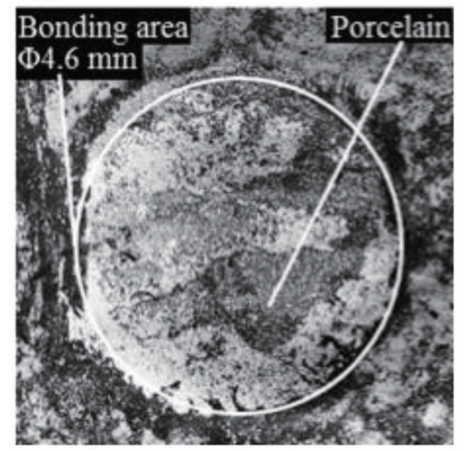

(b)

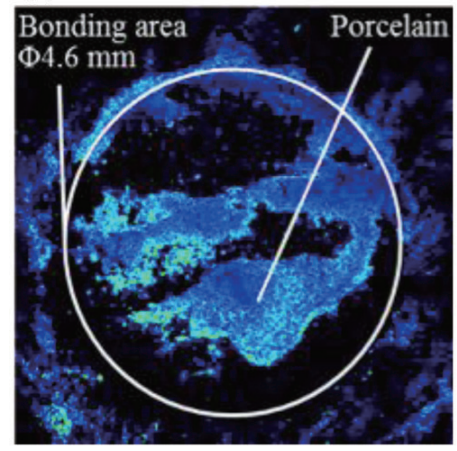

(c)

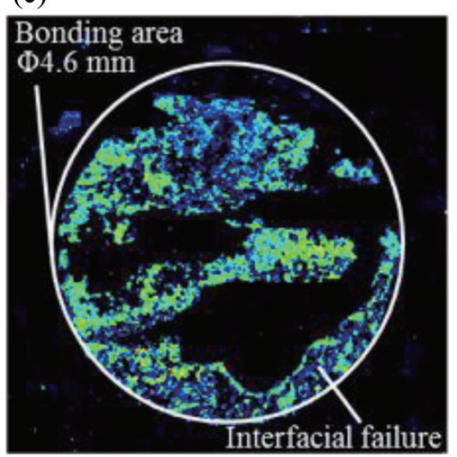

(d)

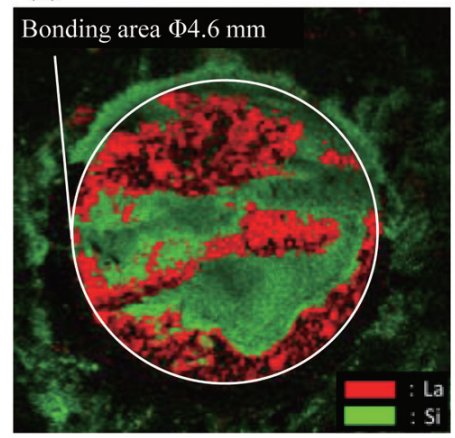

Conventional (e)

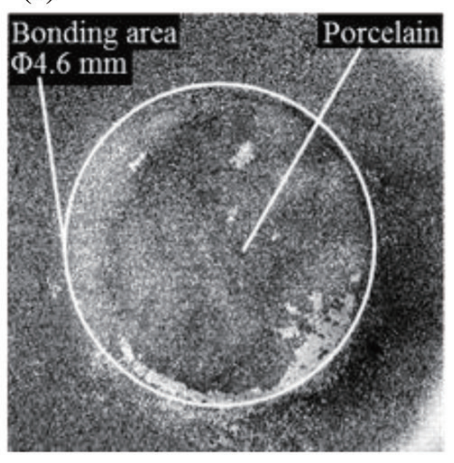

(f)

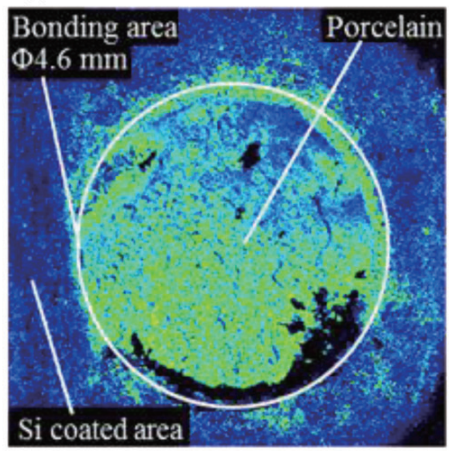

(g)

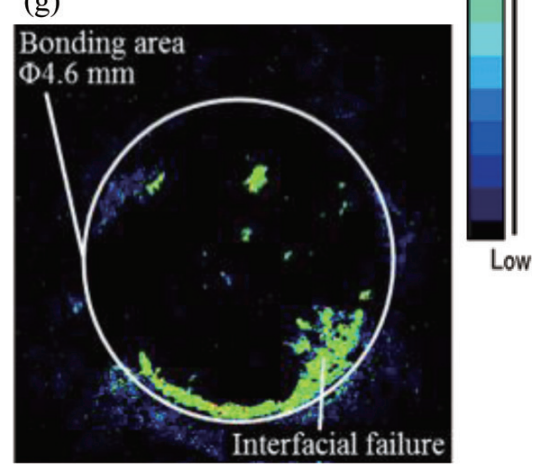

(h)

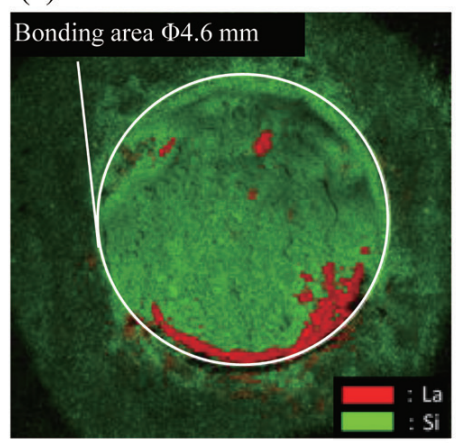

Silica-coating with bonding agent

Fig. 3 (a) BSE image, (b) Si mapping, (c) La mapping, (d) superimposed image Si and La mappings of fracture surface in conventional group. (e) BSE image, (f) Si mapping, (g) La mapping, (h) superimposed image of La and Si mappings of fracture surface in Si-coating with bonding agent group.

Red and green area of superimposed image shows La and Si mapping. Circle in Figure shows bonding area. 
Table 3 Cohesive failure ratios (\%) in conventional group and silica-coating with bonding agent group

\begin{tabular}{ccc}
\hline Surface treatment & Conventional & Silica-coating with bonding agent \\
\hline Cohesive failure ratio (SD) & $43.3(15.3)^{\mathrm{a}}$ & $67.4(13.6)^{\mathrm{b}}$ \\
\hline
\end{tabular}

Significantly differences are visualized with different letters.

a,b Significantly different $(p<0.01)$.

Table 4 Areas where elements were undetectable in conventional group and silica-coating with bonding agent group (\%)

\begin{tabular}{ccc}
\hline Surface treatment & Conventional & Silica-coating with bonding agent \\
\hline Area of undetected elements (SD) & $27.3(15.3)^{\mathrm{a}}$ & $8.9(6.6)^{\mathrm{b}}$ \\
\hline
\end{tabular}

Significantly differences are visualized with different letters.

a,b Significantly different $(p<0.01)$.

Table 5 Contact angles $\left(^{\circ}\right)$ of titanium surface for alumina sandblasting group and silica-coating group

\begin{tabular}{ccc}
\hline Surface treatment & Alumina sandblasting & Silica-coating \\
\hline${\text { Contact angle }\left(^{\circ}\right)}$ & $10.6(0.3)^{\mathrm{a}}$ & $3.4(0.4)^{\mathrm{b}}$ \\
\hline
\end{tabular}

Significantly differences are visualized with different letters.

a,b Significantly different $(p<0.01)$.

group (26.0 \pm 2.8 vs. $22.1 \pm 3.1 \mathrm{MPa} ; p<0.01)$.

Residual porcelain was macroscopically obvious in the fracture surfaces of all specimens. Dark areas in BSE images indicated the cohesive failure of the porcelain (Figs. 3-a and e).

The results of element analysis of fracture surfaces are shown in Fig. 3. Element analysis were examined $\mathrm{Si}$ mapping (Figs. 3-b and f) and La mapping (Figs. 3-c and g). In addition, superimposed images of the Si and La were investigated (Figs. 3-d and h).

Element analysis of the fracture surfaces after the test revealed high levels of $\mathrm{Si}$ in both conventional and silica-coating with bonding agent groups (Figs. 3-b and f). High levels of La were also detected in both conventional and silica-coating with bonding agent groups (Figs. 3-c and g). Superimposed images of the Si and La detected on the fracture surface revealed areas where La and Si were detected in contrast to the conventional and silica-coating with bonding agent groups (Figs. 3-d and h). Black regions without Si or La were evident in the bonded area (Figs. 3-d and h).

The results of cohesive failure ratios are shown in Table 3. Silica-coating with bonding agent group $(67.4 \pm 13.6 \%)$ was significantly higher than the conventional group $(43.3 \pm 15.3 \%)(p<0.01)$.

The conventional group $(27.3 \pm 15.3 \%)$ was significantly higher ratios of regions without Si or La in the bonding areas than silica-coating with bonding agent group $(8.9 \pm 6.6 \%)(p<0.01)$ (Table 4$)$.

The results of contact angles are summarized in Table 5. The silica-coating group $\left(3.4 \pm 0.4^{\circ}\right)$ was smaller than alumina sandblasting group $\left(10.6 \pm 0.3^{\circ}\right)(p<0.01)$.
The results of observation of treated surface are shown in Fig. 4.

The specimens shown in Figs. 4-a, c and e were observed from above. In addition, the specimens shown in Figs. 4-b, d and $\mathrm{f}$ were observed at an angle of $60^{\circ}$. Less microscopic structural changes were evident after polishing titanium surfaces under running water using \#600 waterproof abrasive papers (Figs 4-a and b). Rough irregular undulations were observed with grooves about 1,250-nm deep after alumina sandblasting (Figs. 4-c and d). After silica-coating, grooves about 1,250-nm deep, observed in alumina sandblasting, were not noted, and, instead, regular 200-300-nm nanoscopic foamy structures were observed (Figs. 4-e and f).

\section{DISCUSSION}

In generally, there is a three-point bending test (ISO 9693) as a major test of the bond strength of porcelain fused to the metal ${ }^{33)}$. However, Gilbert et al. used the shear bond strength test and three-point bending test to evaluate the bond strength of titanium and porcelain, and reported that the variation of the shear bond strength test was smaller than that of the three-point bending test ${ }^{30)}$. Therefore, the bond strength at the interface between titanium and porcelain was evaluated using the shear bond strength test in this study.

The porcelain specimens of the same size were fired, which were mounted on titanium specimens. These procedures enabled to stabilize mechanical properties of dentin porcelain. In addition, the bonding area could be standardized because an excess part of the opaque 
(a)

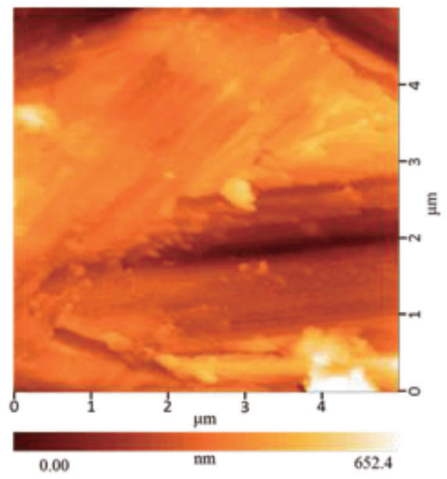

(c)

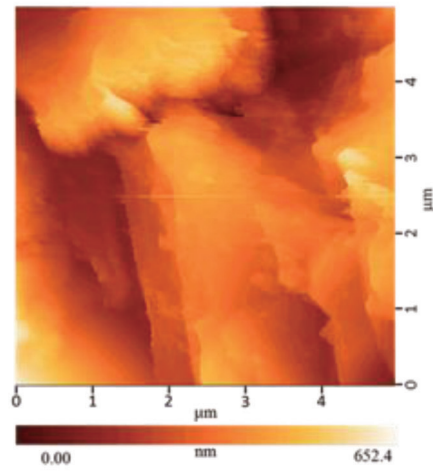

(e)

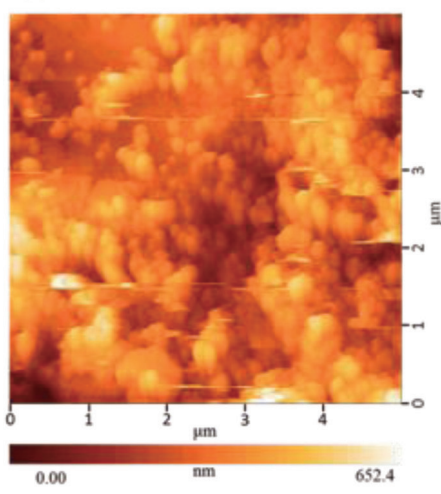

(b)

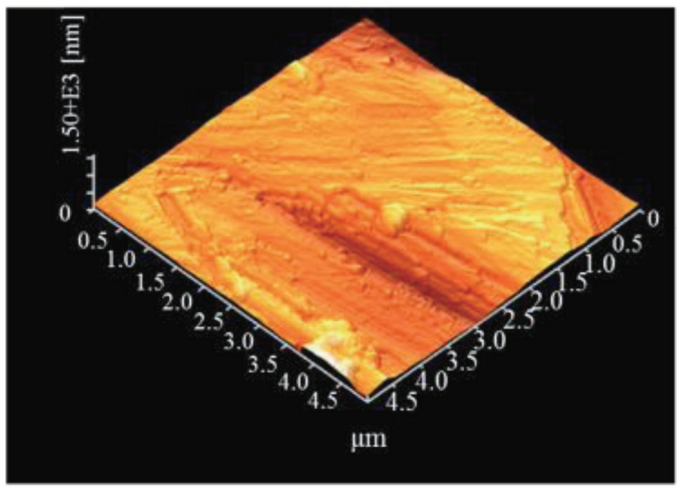

(d)

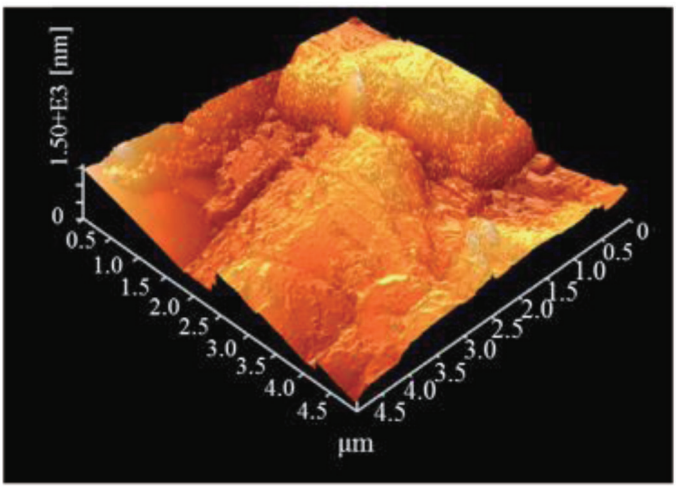

(f)

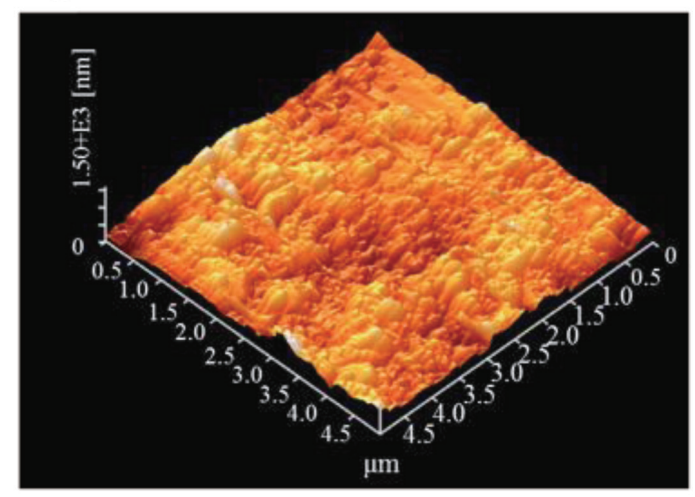

Fig. 4 AFM image of surface in each groups.

(a) (b), Polishing; (c) (d), Alumina sandblasting; (e) (f) Silica-coating. Scale bar means depth.

porcelain was removed easily. Thus, the porcelain application procedure might reduce variation in this study.

Sandblasting is a simple method of mechanically interlocking a titanium surface with porcelain. Larger alumina particles lead to a rougher the titanium surface, which promotes the mechanical interlocking ${ }^{34)}$. Golebiowski et al. reported that $110-\mu \mathrm{m}$ alumina particles are optimal for improving the bond strength of titanium and porcelain ${ }^{35)}$. However, Derand et al. reported that sandblasting with alumina facilitates the embedding of alumina particles in the titanium surface, causing microcracks and reducing the bond strength of both the titanium and porcelain ${ }^{29,30)}$.

In the present study, we examined the effects of porcelain bond strengths on tribochemical silica-coated $\mathrm{CAD} / \mathrm{CAM}$ pure titanium. Zinelis et al. reported that the bonding agent of initial Ti effectively controlled the oxidized layer, although a thick oxidized layer was observed on titanium surface depending on the type of 
bonding agent ${ }^{36}$. Also, the results of the present study demonstrated that the bonding agent of initial $\mathrm{Ti}$ might effectively controlled the excessive oxidation of titanium.

Haag et al. reported that there were no significant differences between the bond strength of titanium and porcelain with and without thermo-cycling ${ }^{21}$. Therefore, thermo-cycling did not be conducted in this study.

Element analysis of fracture surfaces was conducted to investigate fracture pattern. The Si-detected areas corresponded to the areas with residual porcelain observed with the naked eye and the dark areas on the BSE image (Figs. 3-a, b, e, and f). Thus, the Si detected on the fracture surface is derived from porcelain, suggesting that the cohesive failure of porcelain might have occurred in the Si-detected areas.

Some areas in both groups were devoid of both $\mathrm{Si}$ and $\mathrm{La}$, indicating titanium exposure because neither porcelain nor bonding agent was present on the surface.

In the present study, black areas were observed in the fracture surface after testing in the silicacoating with bonding agent group, suggesting slight titanium exposure (Fig. 3-h). However, cohesive failure of porcelain accounted for the majority of the fracture surface, suggesting a small area with $\mathrm{Si}$ of the silicon layer peeled off from the titanium surface. Kern and Thompson reported that Si remains on the surface of tribochemical silica-coated titanium after ultrasonic cleaning, suggesting that $\mathrm{Si}$ is tightly bound to the titanium surface ${ }^{26)}$. Thus, we presumed that the silica layer was firmly bound to the titanium surface after porcelain firing.

Oka et al. reported that sodium, silicon, calcium, and barium in porcelain diffuse into titanium oxide during porcelain firing ${ }^{37)}$. These elements form complex oxides with titanium that become involved in titanium binding to porcelain ${ }^{36-38)}$. Wang et al. used TEM to investigate the bond strength of porcelain to a $\mathrm{Si}_{3} \mathrm{~N}_{4}$-coated titanium surface, and found that titanium silicide formed at the interface between the titanium and $\mathrm{Si}_{3} \mathrm{~N}_{4}$ layer and silicon oxide $\left(\mathrm{SiO}_{2}\right)$ was formed at the interface with the outer surface where the $\mathrm{Si}_{3} \mathrm{~N}_{4}$ layer was bound to porcelain $^{399}$.

The cohesive failure ratio of porcelain was significantly higher in the silica-coating with bonding agent group than in the conventional group. This could be explained as element diffusion between the silicon layer and the porcelain and the formation of complex oxides that might have resulted in robust titanium binding to porcelain.

King et al. reported that close contact between metal and porcelain was obtained by improving the wetting of the metal surface ${ }^{40)}$. In the present study, the titanium exposure rates on the fracture surface after testing were compared, demonstrating a significantly lower rate in the silica-coating with bonding agent group than in the conventional group (Table 3). Thus, in the silica-coating with bonding agent group, tribochemical silica-coating may have improved the wetting on titanium surface and increased compatibility between titanium and the bonding agent.

Contact angles were measured to examine wetting on the treated surface, contact angle in the silicacoating group was smallest (Table 4). Thus, the silicacoated surface might be more hydrophilic than the sandblasted surface. In addition, the contact angle of the silica-coating was less than $10^{\circ}$, suggesting superhydrophilicity on the silica-coated surface.

Nanostructural changes due to improved wetting were examined using an atomic force microscope. Papadopoulos et al. reported that alumina becomes embedded in the titanium surface after sandblasting and forms a rough surface ${ }^{34)}$. The present study also found that alumina sandblasting caused irregular undulations on the titanium surface.

Rammelsberg et al. reported that silica-coating was significantly higher bond strength of titanium and porcelain than alumina sandblasting ${ }^{41)}$. Surface structure analysis revealed silica-coating surface was different from alumina sandblasting surface. In addition, the foamy structure might have improved bond strength of titanium and porcelain.

Thus, after tribochemical silica-coating, besides deep irregular undulations, regular nanostructures may have been formed by particles with a foamy structure.

Surface wetting, as well as surface chemical properties, is influenced by the fine geometric structure of the surface ${ }^{42)}$. Fine, regular grooves on the surface of snail shells range in size from $\mathrm{nm}$ to $\mathrm{mm}$, form a fractal structure and render the shell hydrophilic. These structural properties have been industrially applied to develop a nanohydrophilic antifouling technology ${ }^{433}$. The regular silica layer formed by the nanoscopic foamy structure in the silica-coating also formed a fractal structure like that of the snail shell, suggesting that the nanostructure is involved in superhydrophilicity. The foamy particles seemed to be silicon, suggesting that superhydrophilicity was rendered through hydrogen bonding of the hydroxyl group of the silicon to water.

Thus, unlike routine alumina sandblasting, tribochemical silica-coating effectively modified CAD/ CAM pure titanium into a superhydrophilic fractal structure that was involved in improving the bond strength of porcelain.

\section{CONCLUSIONS}

This study of the effects of a tribochemical silica-coating on the surface of $\mathrm{CAD} / \mathrm{CAM}$ pure titanium and the bond strength of porcelain found the following.

1. Silica-coating results in a nanoscopic regular foamy structure that renders the surface of $\mathrm{CAD} /$ CAM pure titanium superhydrophilic, which is clearly different from the irregular surface generated by alumina sandblasting.

2. Silica-coating combined with a bonding agent can significantly improve the bond strength of $\mathrm{CAD} /$ CAM pure titanium and porcelain. 


\section{ACKNOWLEDGMENTS}

We thank Shusaku OKADA, of Kanagawa Dental University, and Masahiko MITSUHASHI of the Kanagawa Industrial Technology Center for generous support and valuable advice.

\section{REFERENCES}

1) Magnusson B, Bergman M, Bergman B, Söremark R. Nickel allergy and nickel-containing dental alloys. Scand J Dent Res 1982; 90: 163-167.

2) Hey J, Beuer F, Bensel T, Boeckler AF. Metal-ceramic-fixed dental prosthesis with CAD/CAM-fabricated substructures: 6-year clinical results. Clin Oral Investig 2013; 17: 14471451.

3) Hey J, Beuer F, Bensel T, Boeckler AF. Single crowns with CAD/CAM-fabricated copings from titanium: 6-year clinical results. J Prosthet Dent 2014; 112: 150-154.

4) Boeckler AF, Lee H, Stadler A, Setz JM. Prospective observation of $\mathrm{CAD} / \mathrm{CAM}$ titanium ceramic single crowns: a three-year follow up. J Prosthet Dent 2009; 102: 290-297.

5) Lovgren R, Andersson B, Carlsson GE, Odman P. Prospective clinical 5-year study of ceramic-veneered titanium restorations with the Procera system. J Prosthet Dent 2000; 84: 514-521.

6) Boeckler AF, Lee H, Psoch A, Setz JM. Prospective observation of CAD/CAM titanium-ceramic-fixed partial dentures: 3-year follow-up. J Prosthodont 2010; 19: 592-597.

7) Marklund S, Bergman B, Hedlund SO, Nilson H. An intraindividual clinical comparison of two metal-ceramic systems: a 5-year prospective study. Int J Prosthodont 2003; 16: 70-73.

8) Kaus T, Probster L, Weber H. Clinical follow-up study of ceramic veneered titanium restorations-three-year results. Int J Prosthodont 1996; 9: 9-15.

9) Walter M, Reppel PD, Boning K, Freesmeyer WB. Six-year follow-up of titanium and high-gold porcelain-fused-to-metal fixed partial dentures. J Oral Rehabil 1999; 26: 91-96.

10) Bergman B, Nilson H, Andersson M. A longitudinal clinical study of Procera ceramic-veneered titanium copings. Int J Prosthodont 1999; 12: 135-139.

11) Oyafuso DK, Ozcan M, Bottino MA, Itinoche MK. Influence of thermal and mechanical cycling on the flexural strength of ceramics with titanium or gold alloy frameworks. Dent Mater 2008; 24: 351-356.

12) Yilmaz H, Dincer C. Comparison of the bond compatibility of titanium and an NiCr alloy to dental porcelain. J Dent 1999; 27: 215-222.

13) Probster L, Maiwald U, Weber H. Three-point bending strength of ceramics fused to cast titanium. Eur J Oral Sci 1996; 104: 313-319.

14) Adachi M, Mackert JR, Jr., Parry EE, Fairhurst CW. Oxide adherence and porcelain bonding to titanium and Ti-6Al-4V alloy. J Dent Res 1990; 69: 1230-1235.

15) Togaya T, Suzuki M, Tsutsumi S, Ida K. An application of pure titanium to the metal porcelain system. Dent Mater J 1983; 2: 210-219.

16) Akagi K, Okamoto Y, Matsuura T, Horibe T. Properties of test metal ceramic titanium alloys. J Prosthet Dent 1992; 68: 462-467.

17) Kupper H. Pure titanium as an alternative material in restorative dentistry. QDT Yearbook 1992: 143-152.

18) Miyakawa O, Watanabe K, Okawa S, Nakano S, Kobayashi M, Shiokawa N. Layered structure of cast titanium surface. Dent Mater J 1989; 8: 175-185.

19) Boning K, Walter M. Ceramo-metallic bond of cast titanium. Dtsch Zahnarztl Z 1991; 46: 750-753.
20) Oshida Y, Fung LW, Isikbay SC. Titanium-porcelain system. Part II: Bond strength of fired porcelain on nitrided pure titanium. Biomed Mater Eng 1997; 7: 13-34.

21) Haag P, Andersson M, Nilner K. Porcelain bonding to titanium with two veneering principles and two firing temperatures. Swed Dent J 2013; 37: 143-151.

22) Zhang CC, Ye JT, Zhang YP, Liao JK, Li BH. Effect of titanium preoxidation on wrought pure titanium to ceramic bond strength. J Prosthet Dent 2013; 109: 106-112.

23) Lin MC, Tung KL, Lin SC, Huang HH. Bonding of dental porcelain to non-cast titanium with different surface treatments. Dent Mater J 2012; 31: 933-940.

24) Troia MG Jr, Henriques GE, Mesquita MF, Fragoso WS. The effect of surface modifications on titanium to enable titaniumporcelain bonding. Dent Mater 2008; 24: 28-33.

25) Guggenberger R. Rocatec system —adhesion by tribochemical coating]. Dtsch Zahnarztl Z 1989; 44: 874-876.

26) Kern M, Thompson VP. Effects of sandblasting and silicacoating procedures on pure titanium. J Dent 1994; 22: 300306.

27) Ino S, Toyoda M, Niiya T, Tamura T, Shibata T, Atsumi M, Hamano M. The effect of silica coating on the bonding strength of veneering composite resin to dental alloys. J Jpn Prosthodont Soc 2003; 47: 292-300.

28) GC EUROPE. GC Initial Ti Technical Manual. 2008

29) Derand T, Hero H. Bond strength of porcelain on cast vs. wrought titanium. Scand J Dent Res 1992; 100: 184-188.

30) GilbertJL, Covey DA, Lautenschlager EP. Bond characteristics of porcelain fused to milled titanium. Dent Mater 1994; 10: 134-140.

31) International Organization Standardization. Polymer-based crown and bridge materials: ISO 10477. ISO, 2004.

32) Rasband WS. ImageJ, U. S. National Institutes of Health, Bethesda, Maryland, USA, http://imagej.nih.gov/ij/, 19972012.

33) International Organization Standardization. Metal-ceramic dental restorative systems: ISO 9693. ISO, 1999.

34) Papadopoulos T, Tsetsekou A, Eliades G. Effect of aluminium oxide sandblasting on cast commercially pure titanium surfaces. Eur J Prosthodont Restor Dent 1999; 7: 15-21.

35) Golebiowski M, Wolowiec E, Klimek L. Airborne-particle abrasion parameters on the quality of titanium-ceramic bonds. J Prosthet Dent 2015; 113: 453-459.

36) Zinelis S, Barmpagadaki X, Vergos V, Chakmakchi M, Eliades G. Bond strength and interfacial characterization of eight low fusing porcelains to cp Ti. Dent Mater 2010; 26: 264-273.

37) Oka K, Hanawa T, Kon M, Lee HH, Kawano F, Tomotake Y, Matsumoto N, Asaoka K. Effect of barium in porcelain on bonding strength of titanium-porcelain system. Dent Mater J 1996; 15: 111-120.

38) Hanawa T, Kon M, Ohkawa S, Asaoka K. Diffusion of elements in porcelain into titanium oxide. Dent Mater J 1994; 13: $164-173$

39) Wang RR, Welsch GE, Monteiro O. Silicon nitride coating on titanium to enable titanium-ceramic bonding. J Biomed Mater Res 1999; 46: 262-270.

40) King BW, Tripp HP, Duckworth WH. Nature of adherence of porcelain enamels to metals. J Am Ceram Soc 1959; 42: 504525.

41) Rammelsberg P, Aschl I, Pospiech P. Verbundfestigkeit niedrigschmelzender Keramiken zu Titan unter Berücksichtigung der Oberflächenkonditionierung. Dtsch Zahnärztl Z 53; 3: 1998.

42) Onda T, Shibuichi S, Satoh N, Tsujii K. Application of fractals to surface science. Oyobuturi 1995; 64: 788-792.

43) Isu N. Stain-free housing materials inspired from snail shell surface. J Jpn Weld Soc 2009; 78: 187-190. 